\title{
Introducing a legal mandate for basic medical education accreditation in Korea
}

\section{Ducksun Ahn}

Department of Medical Humanities and Department of Plastic Surgery, Korea University College of Medicine, Seoul, Korea

South Korea's medical education history is intertwined with its explosive economic growth. In the 1980s, the Korean government opened the medical education industry to the private sector. The desired results for the schools were twofold: (1) to meet the needs of the healthcare system with a growing economy; and (2) to generate positive economic gain in local communities. These intentions were clear in the government's instructions: In order to open a medical school, the founding body had to also build a 500-bed teaching hospital in the same region. The government, in return, would provide tax exemptions or deductions to the hospital by categorizing it as an educational facility. With the flourishing economy, many schools and hospitals were established across South Korea over the following two decades.

However, the prolific growth came at a price. Preying on the students' hopes of becoming medical professionals, medical schools began enrolling students, without providing them with the basic facilities. Arguing that the construction of the teaching hospital would be completed by the time students needed clinical education (in 5-6 years); schools lured prospective students to their barely-completed medical schools. This phenomenon was particularly worrisome because medical schools in Korea sit at an intersection of nonprofit and for-profit management practices. While all Korean medical schools must be nonprofit operations by law, private schools often operate as a for-profit organization. With hefty tuition fees being generated through the new student body, the new private schools saw little reason to forego a revenue generating opportunity.

In order to regulate and implement quality assurance structures, South Korea introduced accreditation for basic medical education (BME) in 1999. However, neither the government nor the society in general had any experience nor vision of what quality assurance management should entail. Before 1999, no inquiries had been made about the quality of education programs or the competencies of physicians.

The medical society felt that graduates from schools with inadequate resources and poor school governance would negatively affect the profession, and ultimately the patients. With the help of other stakeholders, the
Received: December 14, 2015 • Revised: December 15, 2015 • Accepted: December 15, 2015 Corresponding Author: Ducksun Ahn (http://orcid.org/0000-0003-2762-0026)

Department of Medical Humanities and Department of Plastic Surgery, Korea University Anam Hospital, Korea University College of Medicine, 73 Inchon-ro, Seongbuk-gu, Seoul 02841, Korea Tel: +82.2.920.5342 Fax: +82.2.921.4068 email: dsahn@korea.ac.kr
Korean J Med Educ 2016 Mar; 28(1): 5-7.

http://dx.doi.org/10.3946/kjme.2016.3

eISSN: 2005-7288

(C) The Korean Society of Medical Education. All rights reserved. This is an open-access article distributed under the terms of the Creative Commons Attribution Non-Commercial License (http:// creativecommons.org/licenses/by-nc/3.0/), which permits unrestricted non-commercial use, distribution, and reproduction in any medium, provided the original work is properly cited. 
Korean Medical Association established quality assurance agencies such as The Korean Hospital Association, the Korean Society of Medical Education, and the Korean Association of Medical Colleges. The year 1997 saw the first quality assurance assessment of medical education. Transforming themselves into a committee, this group of assessors actively benchmarked foreign quality assurance systems and adapted them to the Korean environment.

After the initial trial in 1999, a full scale accreditation was launched in 2000. Since then, the accreditation process has evolved from an input-oriented system to a process-oriented system, to its current outcome-oriented format. The number of prerequisites prescribed by accreditation standards was increased from the initial 50 to the current 97 items. In the last two decades, 41 medical schools have acquired complete accreditation over the course of three cycles, and have become fully accredited, with the exception of two schools that still have some unsolved issues with the school management. One has nonaccredited status, and the other is on probation. Meanwhile, the accrediting committee became incorporated as the Korean Institute of Medical Education and Evaluation (KIMEE), under the Ministry and Health in 2004. KIMEE was recently certified by the Ministry of Education as an official accreditor for basic medical education in 2014. Parallel to this internal progress, the Korean accreditation process has also undergone internal and external evaluation for quality assurance. Meanwhile, a national, large scale objective structured clinical examination (OSCE) was introduced as part of the licensing examination to improve practical clinical education in the last 2 years of medical curriculum in 2010. This was possible because accreditation standards prescribed the installation of skill labs and OSCE at medical schools.

The internal evaluation of the accreditation process provides evidence to show how medical education has improved in South Korea. In the evaluation, the Korean Association of Medical Colleges acknowledges the advantages of providing accreditation to medical schools. However, an internal evaluation alone was deemed insufficient to diagnose where Korean accreditation stood in the global environment. Therefore, a meta-evaluation by an external body was conducted to gain an insight from a global perspective. The goal of accreditation is to improve the quality of education and to institute self-regulation. The meta-evaluation team discovered that accreditation had been carried out fairly well but it did not add value to medical education or raise its standards. While facilities and faculty capacity for education had improved, the stakeholders' perception of the inherent value of education did not change. Education was perceived as secondary to research or clinical service in all the medical schools. The current accreditation of basic medical education achieved the regulatory aspect of accreditation, but did not generate innovation to the degree that KIMEE desired.

However, there are certain limitations related to the appraisal of accreditation in Korea. It has been only 15 years since the KIMEE started providing accreditation to medical colleges. Accreditation, a periodic investigation from an independent external body, only occurs once every 4 to 6 years in a medical school. This gap between each accreditation visit poses some problems. Until 2012, the process did not include any progress checks built in to verify compliance. Additionally, members of the medical school deanery had either changed or did not fully recall the details of the previous visit. The short duration in office of each dean also contributed to this discontinuity. Thus, the current system of external accreditation often undergoes difficulty in coordinating with the internal program evaluation system.

The overall result, however, from the meta-evaluation on BME accreditation in 2012 is clear: ongoing internal 
program evaluations by medical schools for quality improvement are vital for quality assurance. Therefore, continuous quality improvement (CQI) of the BME program should be the center of the accreditation process. CQI is already a prerequisite for medical schools according to new accreditation standards. The most recent version of accreditation standards from the World Federation for Medical Education highlights the importance of CQI. There are three areas of accreditation for CQI: program evaluation, governance and administration, and continuous renewal. These three areas form the basis of CQI.

The new standards also require progress reports to be submitted every 2 years between the accreditation visits. However, these changes were only implemented in 2012. So far (2012-2015), the compliance efforts from medical schools for CQI measures vary from nil to a creation of a CQI unit with good standing within the medical school administration. Many schools with some degree of CQI practice has had its CQI capacity transferred from its teaching hospital and the hospital's accreditation process to an international agency.

It is still too early to expect fully functioning CQI units within medical schools. CQI is rather new for most medical schools and educators, even though the concept of CQI has been introduced in the industrial sector since the 1960s. Interestingly, even schools with CQI practice in university hospitals had difficulty transferring the knowledge and capacity from the hospital setting to the school. This shows that there is a significant disconnect between education and practice. Ideally, medical education should be a continuum. Any issues raised from practice should be reflected into improving resident training, and it should also become incorporated in BME. The feedback loop has to be so designed that the practice change can be initiated from the BME level. The ideal end-goal of CQI is perhaps an effective two-way communication cycle between school and hospital, providing feedback and initiating improvements in one other. Currently, neither KIMEE nor the medical schools themselves have enough capacity to execute and evaluate the CQI efforts of medical schools. It is only recently that the importance of CQI has been stressed and implemented in all aspects of medical education.

This external perspective on the educational program of the school has yielded precious insights into the areas of improvement. Building a sound CQI practice in a medical school is a daunting task because that requires a change in the organizational culture at the institutional level. New laws for mandatory accreditation across all healthcare practices, including medicine, dentistry, traditional medicine, and nursing, have recently been passed by legislation in Korea. Historically, South Korea is not accustomed to relying on professional-led selfregulation. It is a general perception among Koreans that only the government has the authority to regulate public affairs. In this sense, these new laws will strongly empower current accreditation practices. These unprecedented measures is the levying mandate for health education providers and accreditors to accomplish the goal of educational change not only to safely produce competent graduates from medical school, but also to change current practices for increased safety of patients and the society.

Acknowledgements: None.

Funding: None.

Conflicts of interest: None. 